\title{
A abordagem sociocultural e a formação docente: construindo conhecimento relevante e contextual
}

\section{Sociocultural Approach and Teacher Education: Constructing Relevant and Contextual Knowledge}

Pedro Augusto de Lima Bastos*

*Instituto Federal do Norte de Minas Gerais (IFNMG), Arinos, Minas Gerais / Brasil pedro_itapaci@hotmail.com

https://orcid.org/0000-0002-7736-4895

Laryssa Paulino de Queiroz Sousa**

**Universidade Federal de Goiás (UFG), Goiânia, Goiás / Brasil

laryssa.paulino1@gmail.com

https://orcid.org/0000-0001-6790-5611

RESUMO: Este estudo de caso qualitativo objetiva investigar o processo de construção de conhecimento entre um professor em formação continuada e uma professora universitária a partir da mediação dialogada em sessões reflexivas, da escrita de um diário pessoal e de informações provenientes de dois planos de aula. Utilizamos pressupostos da formação docente na perspectiva sociocultural para analisar, de forma situada e contextual, dois momentos em que o professor em formação continuada modificou sua prática devido à mediação dialogada à qual teve acesso. A análise do material empírico permite observar a importância de considerar a formação de professores/as como distribuída entre pessoas e ferramentas, além de evidenciar a significância de momentos formais e informais na construção de conhecimento relevante para o professor em formação, especialmente por meio da mediação estratégica e do diálogo colaborativo.

PALAVRAS-CHAVE: Abordagem sociocultural, formação continuada de professores/as, construção de conhecimento.

ABSTRACT: This qualitative case study aims to investigate the process of knowledge construction between an in-service teacher and a university professor by focusing on dialogic mediation in reflective sessions, a personal diary, and information from two lesson plans. We draw on teacher education studies from a sociocultural perspective to analyze, in a contextual and situated way, 
two moments when the in-service teacher changed his teaching practice due to dialogic mediation to which he had access. The analysis of the empirical material allowed us to observe the importance of considering teacher education as distributed across people and tools, besides showing the significance of formal and informal moments in the construction of relevant knowledge for the teacher, especially through strategic mediation and collaborative dialogue.

KEYWORDS: Sociocultural approach, continuous teacher education, knowledge construction.

\section{Introdução}

A pesquisa em formação de professores/as vivenciou grandes transformações nas últimas décadas. Vieira-Abrahão (2012) afirma que tais transformações se devem a mudanças em nossa percepção de mundo e nas perspectivas epistemológicas de pesquisa. Essas mudanças modificam a forma como vemos a aprendizagem, que, por exemplo, passou de uma visão mais behaviorista, para uma mais cognitiva e, depois, sociocultural (JOHNSON, 2009). A perspectiva sociocultural contrasta com a perspectiva cognitiva de origem positivista por ela não definir "a aprendizagem como um processo psicológico isolado e interno na mente do[/a] aprendiz, livre dos contextos sociais e físicos em que ela ocorre" (LENNEBERG, 1967, apud JOHNSON, 2009, p. 7). Sendo assim, a abordagem sociocultural mostra-se relevante, pois, como Figueiredo (2018), entendemos que o conhecimento é gerado dentro e a partir da interação entre seres humanos, em seu meio social.

O paradigma positivista, em que a perspectiva cognitiva se baseia, entende a realidade como separada dos contextos sociais e históricos. O conhecimento é visto como um objeto identificável, mensurável, generalizável e exterior ao indivíduo. Vieira-Abrahão (2012, p. 458) pontua que, para o positivismo, "o interesse da pesquisa em formação de professores[/as] se volta para a identificação do que profissionais eficientes realizam na sala de aula, de forma a maximizar a aprendizagem do[/a] aluno[/a]", isto é, o interesse consistia em identificar generalizações no comportamento de professores/as para que técnicas específicas pudessem ser ensinadas em cursos de treinamento. Aliás, os termos treinamento e formação possuem um caráter ideológico distinto, pois o primeiro parte de um paradigma positivista que está mais preocupado com o produto, enquanto o segundo direciona um enfoque maior ao processo de aprender a ensinar. 
A perspectiva sociocultural é principalmente baseada nos estudos de Vygotsky $(1993,1998)$. Vários/as estudiosos/as da Linguística Aplicada têm utilizado as premissas e os principais conceitos da abordagem sociocultural para compreender o processo de ensino e aprendizagem de línguas (AHMED, 1994; DONATO, 2000; FIGUEIREDO, 2018; LANTOLF; APPEL, 1994; SOUSA, 2016; SOUSA et al., 2019; SWAIN, 2000) e o processo de formação de professores/as (JOHNSON, 2006, 2009; JOHNSON; GOLOMBEK, 2011; MATEUS, 2013a, 2013b; MATEUS; EL KADRI; GAFFURI, 2014; SILVESTRE, 2014; VIEIRA-ABRAHÃO, 2012). Neste artigo, tentamos olhar para a formação docente por meio da abordagem sociocultural. Utilizamos o material empírico gerado em parte de uma pesquisa de mestrado, com o objetivo de analisar o processo de construção de conhecimento entre um professor em formação continuada e uma professora universitária a partir da mediação dialogada em sessões reflexivas, da escrita de um diário pessoal e de informações provenientes de dois planos de aula.

Este texto está dividido em cinco partes. Primeiramente, ele possui esta parte introdutória na qual iniciamos a discussão e apresentamos nosso objetivo. $\mathrm{Na}$ fundamentação teórica, enfocamos a teoria vygotskiana sobre o desenvolvimento mental e discutimos alguns conceitos relacionados ao ensino de línguas e, especialmente, à formação de professores/as de línguas, que é o assunto central deste artigo. Na terceira parte, contextualizamos o estudo e demonstramos como o material empírico foi gerado. Depois, refletimos sobre alguns eventos de formação docente em que a mediação dialógica esteve presente e influenciou a construção de conhecimento entre o professor em formação continuada e a professora universitária. No final, discorremos sobre algumas considerações concernentes ao processo de construção dialogada de conhecimento.

\section{Fundamentação teórica}

Vygotsky (1998) propõe uma mudança de paradigma nos estudos da psicologia em relação à percepção, até então vigente, sobre o desenvolvimento. O salto teórico proposto pelo autor nos permite perceber o desenvolvimento como algo que parte do social para o individual, isto é, do exterior para o interior. Para Donato (2000, p. 45), 
[d]entro da perspectiva cognitiva de aquisição, o indivíduo é visto como o único canal pelo qual o conhecimento é adquirido. $\mathrm{Na}$ abordagem sociocultural, no entanto, a aprendizagem, incluindo a aprendizagem de segundas línguas, é um processo semiótico atribuído à participação em atividades socialmente mediadas.

O acontecimento de qualquer atividade cognitiva é social e depende da interação para acontecer. De acordo com Vygotsky (1986, apudLANTOLF; APPEL, 1994, p. 4), é "na interação entre corpos pensantes (humanos) e entre corpos pensantes e objetos (humanos e artefatos construídos socioculturalmente)" que podemos explicar o processo de funcionamento do cérebro. A interação entre humanos e entre humanos e objetos é chamada de mediação social.

A mediação é um conceito crucial na teoria de Vygotsky (1998), pois é a partir dela que ocorre o processo de internalização. Para o autor, os seres humanos são orientados para o controle e a dominação das leis da natureza e de si. No entanto, nós não agimos diretamente sobre a natureza ou sobre nós mesmos/as, mas utilizamos instrumentos e signos para realizar essas tarefas. O instrumento é orientado externamente e "deve necessariamente levar a mudanças nos objetos", ao passo que o signo é orientado internamente, “dirigido para o controle do próprio indivíduo" (VYGOTSKY, 1998, p. 72, 73). Os instrumentos e os signos são ferramentas utilizadas para a mediação social e é a partir dela que ocorre o processo de internalização, ou seja, "a reconstrução interna de uma operação externa” (VYGOTSKY, 1998, p. 74).

O processo de internalização é o que permite a autorregulação, isto é, o controle sobre o seu próprio comportamento (LANTOLF; APPEL, 1994). Vygotsky (1998) divide o comportamento em formas inferiores e superiores, ou seja, instintivas e aprendidas. Piscar o olho, por exemplo, é uma forma de comportamento inferior, ao passo que ler é uma forma de comportamento superior por exigir a mediação social para que ela seja desenvolvida. $\mathrm{O}$ desenvolvimento acontece quando a atividade social interindividual é transformada em funcionamento mental intra-humano (AHMED, 1994).

A mediação social e a internalização acontecem dentro do que Vygotsky (1998, p. 112) chama de Zona de Desenvolvimento Proximal (ZDP), que é 
a distância entre o nível de desenvolvimento real, que se costuma determinar através da solução independente de problemas, e o nível de desenvolvimento potencial, determinado através da solução de problemas sob a orientação de um[/a] adulto[/a] ou em colaboração com companheiros[/as] mais capazes.

Com essa definição, o autor coloca o desenvolvimento como dependente da interação social. Mais importante ainda é que a aprendizagem precede o desenvolvimento. Essa mudança, apesar de pequena, é um ponto crucial da teoria de Vygotsky (1998) por acreditar que o desenvolvimento e a aprendizagem são processos ativos, e, para que o desenvolvimento ocorra, primeiro o indivíduo deve passar pelo processo de aprendizagem. É nessa definição onde está uma das maiores diferenças entre Piaget e Vygotsky (BANKS-LEITE, 2000; VYGOTSKY, 1993), pois, para Piaget, o desenvolvimento é independente da aprendizagem, mas, para Vygotsky, a aprendizagem é o que "resulta em desenvolvimento mental e põe em movimento vários processos de desenvolvimento que, de outra forma, seriam impossíveis de acontecer" (VYGOTSKY, 1993, p. 118).

O uso de testes de QI, por exemplo, para medir a inteligência de alguém, mede o desenvolvimento de ontem, ou seja, o desenvolvimento já completado. Saber o que uma pessoa já faz não nos ajuda muito a saber o que ela poderá aprender a fazer no futuro. Sendo assim, Vygotsky (1998, p. 117, ênfase no original) afirma que “o 'bom aprendizado' é somente aquele que se adianta ao desenvolvimento". Por isso, ele pontua que as formas superiores de comportamento que possuímos vão depender muito do nosso contexto sociocultural, e não somente de estágios fixos de maturação.

Apesar de a ZDP ter causado um salto qualitativo enorme sobre como olhamos o desenvolvimento, o conceito ainda precisava de maior elaboração. Tudge (1990) critica a ZDP por não haver certeza de que o significado criado por dois pares será correto ou mais elevado, mesmo com a presença de um par mais competente do que o outro. $\mathrm{O}$ autor propõe que olhemos para $\mathrm{o}$ processo de interação durante a ZDP, ao invés de assumir simplesmente que o trabalho em pares é benéfico. Além disso, observamos que, como Donato (2000, p. 47) explicita, "a aprendizagem e o desenvolvimento, incluindo os de segunda língua e língua estrangeira, são situados. Essa característica situacional significa que a aprendizagem se desdobra em diferentes formas sob diferentes circunstâncias". Isso quer dizer que não é a ZDP que vai 
indicar a qualidade do produto produzido, mas a situação em que o processo foi realizado.

Já especificamente em relação a pesquisas no contexto de formação docente, Johnson $(2006,2009)$ e Vieira-Abrahão (2012) sinalizam a mudança do paradigma positivista para o paradigma interpretativista. Na perspectiva positivista, o que havia na formação de professores/as era o ensino de técnicas e métodos para a transmissão de conhecimentos. Esse paradigma de pesquisa desconsidera a realidade local e o contexto sócio-histórico por estar baseado em generalizações sobre o que seria um/a bom/boa ou um/a ruim professor/a ou ensino, e, consequentemente, tem sido considerado insuficiente para "explicar as complexidades das vidas mentais dos/as professores/as e os processos de ensino que ocorrem em salas de aula" (JOHNSON, 2006, p. 236). Para Vieira-Abrahão (2012, p. 459), a pesquisa interpretativista considera o conhecimento como algo que é "construído socialmente e emerge das práticas sociais”, perspectiva que se aproxima da abordagem sociocultural.

Dentro da epistemologia sociocultural, Johnson (2009, p. 5) discorre sobre o que essa perspectiva pode oferecer para a formação de professores / as de segunda língua e propõe cinco pontos importantes: 1) docentes como aprendizes do processo de ensinar, que entende o conhecimento sobre ensino como construído em contextos específicos nos quais os/ as professores/as atuam; 2) língua como prática social, que concebe o significado como situado e em mudança contínua; 3) ensino como mediação dialógica, que está relacionada aos processos de externalização e internalização de novos comportamentos e conhecimentos; 4) a relação entre macroestruturas e a profissão docente de segunda língua, que concebe como "as atividades de um/a professor/a formam e são formadas por macroestruturas sociais, culturais e históricas que constituem seu mundo profissional"; e 5) abordagens baseadas em questionamentos, focadas no desenvolvimento profissional, com o intuito de engajar professores/as num processo contínuo de autorreflexão e autocrítica.

Johnson (2009, p. 2) afirma que as mudanças descritas anteriormente tentam promover "práticas responsivas a necessidades locais e individuais". Para a autora, "[c]omo um indivíduo aprende algo, o que é aprendido, e como isso é usado dependerá das experiências anteriores do indivíduo, nos contextos socioculturais em que a aprendizagem acontece, e o que o indivíduo quer, precisa, ou espera fazer com aquele conhecimento" 
(JOHNSON, 2009, p. 2). Isso se relaciona com o que Vygotsky (1998) afirma sobre o desenvolvimento: os seres humanos se desenvolvem a partir do que está disponível em seus contextos sociais. Por fim, um ponto pertinente da pesquisa interpretativista é que ela não nega o que o/a professor/a já sabe ou é capaz de fazer, mas se importa em procurar possibilidades para solucionar ou pelo menos remediar os problemas com os quais os/as professores/as lidam.

A agência, na teoria sociocultural, também é um conceito extremamente relevante (DONATO, 2000). É importante lembrar que

a educação de professores/as não é somente um processo de enculturação em práticas sociais associadas ao ensino, mas também processos dinâmicos de reconstrução e transformação de tais práticas para serem responsivas a necessidades individuais e locais. (JOHNSON, 2009, p. 13).

O processo de formação de professores/as na teoria sociocultural não é tomado como passivo.

Durante a mediação dialógica, a internalização não é a simples mudança do exterior para o interior, pois o indivíduo também sofre transformações e reinterpreta o objeto mediado a seu modo. Isso nos faz ver a importância do agenciamento docente na internalização de determinados comportamentos específicos da profissão, pois é a partir dele que o/a professor/a poderá construir conhecimento útil para seu contexto de ensino. Portanto, como Mateus (2013b, p. 1126) salienta, "agência é sempre uma potencialidade (e não um atributo individual preexistente)".

No caso da aprendizagem de uma segunda língua, Swain (2000) propõe entender o output além do conceito comum de produção. De acordo com a autora, o além do output é o diálogo colaborativo que medeia a construção de conhecimento e a resolução de problemas sobre uma língua por meio dela mesma. A verbalização durante o diálogo colaborativo "focaliza a atenção, externaliza hipóteses, testa-as, fornece possíveis soluções, e medeia a implementação de comportamentos estratégicos como planejamento e avaliação" (SWAIN, 2000, p. 108). Para a autora, esse processo de mediação social por meio da língua intensifica a produção linguística (utilização da língua) e metalinguística (conhecimento sobre a língua). Argumentamos que os aspectos mencionados por Swain (2000) sobre o diálogo colaborativo não 
ocorrem somente no contexto de ensino e aprendizagem de línguas, mas também em ambientes formais e informais de formação docente.

Enquanto, na aprendizagem de línguas, o diálogo colaborativo serve para usar a língua e aprender sobre ela, intensificando seu uso, na formação de professores/as, a mediação entre docentes cria a possibilidade de produção de conhecimentos de forma conjunta e, consequentemente, fomenta a eventualidade de mudanças nas práticas deles/as.

De acordo com Ibiapina (2008a, 2008b, 2016), o trabalho colaborativo entre professores/as deve envolver a formação profissional, a coprodução de conhecimentos e a mudança nas práticas educativas, via mediação uns / umas dos/as outros/as. Um aspecto central da pesquisa colaborativa na formação docente é que o olhar investigativo não é lançado sobre o/a outro/a, mas sim com o/a outro/a (IBIAPINA, 2008a). Assim, busca-se a criação de um ambiente que estimule a discussão, a autonomia e o respeito mútuo. Contudo, é importante salientar que o trabalho colaborativo não significa que os/as professores/as envolvidos/as tenham que desempenhar as mesmas funções, mas que as decisões precisam ser negociadas e tomadas, e a responsabilidade compartilhada de acordo com as necessidades e situações de cada contexto (IBIAPINA, 2008b, 2016).

Ademais, Ibiapina (2008b, p. 32-33) argumenta que "[o] trabalho colaborativo de co-produção de conhecimentos no âmbito da pesquisa em educação e para a educação" envolve "possibilidades de compreensão da prática docente, elemento essencial para o processo de pesquisa, o que supõem que $\mathrm{o}[/ \mathrm{a}]$ pesquisador[/a] trabalhe nos dois campos, o da pesquisa e o da formação".

De acordo com Mateus, El Kadri e Gaffuri (2014), na formação docente de viés colaborativo, os/as docentes envolvidos/as têm em vista o mesmo objetivo e trabalham conjuntamente para alcançá-lo, de modo que são valorizados os diferentes tipos de conhecimento que cada ator/atriz traz para o processo. No entanto, Mateus (2013b, p. 1126) argumenta que é importante definir, "de forma democrática e dialógica, expectativas, modos de atuação [e] possibilidades de contribuição” entre os/as docentes.

Assim, percebemos que há uma mudança de paradigma de pesquisa e de entendimento do que é formação de professores/as quando recorremos a perspectivas embasadas na teoria sociocultural. As teorizações decorrentes dela transformam a formação numa atividade essencialmente dialógica, que envolve a participação ativa dos/as docentes na construção de conhecimento útil e situado. 


\section{O estudo}

Este é um estudo de caso qualitativo (MERRIAM, 1998, 2002) que objetiva analisar o processo de construção de conhecimento entre um professor em formação continuada e uma professora universitária a partir da mediação dialogada em sessões reflexivas, da escrita de um diário pessoal e de informações provenientes de dois planos de aula. Partindo do paradigma qualitativo, perspectiva científica que se alinha muito bem com a abordagem sociocultural, entendemos o significado como algo "socialmente construído pelos indivíduos em interação com seus mundos” (MERRIAM, 2002, p. 3). Para tal, o objetivo da pesquisa qualitativa é "entender os significados que as pessoas têm construído sobre seus mundos e experiências” (MERRIAM, 2002, p. 4-5).

O contexto desta pesquisa é uma sala de aula da graduação em Letras: Inglês, de uma universidade federal. O professor em formação continuada recebeu a anuência da professora regente para ministrar 32 horas-aula e gerar material empírico para sua pesquisa de mestrado sobre formação docente, em 2017, com professores/as em formação universitária. A docente regente assistiu a todas as aulas e gentilmente aceitou realizar sessões reflexivas sobre elas uma vez por semana. Com isso, foi possível refletir sobre a prática pedagógica do professor em formação continuada.

Contamos com material empírico proveniente de três fontes: sessões reflexivas com a professora universitária; diário pessoal escrito pelo professor em formação continuada; e planos de aula feitos pelo professor em formação.

Consideramos essas fontes de pesquisa como ferramentas baseadas numa abordagem questionadora (JOHNSON, 2009). Isso se deve ao fato de a sessão reflexiva e o diário pessoal "criarem o potencial para mediação dialógica continuada entre professores/as quando eles/as se engajam em atividades direcionadas a um objetivo específico" (JOHNSON, 2009, p. 95). Além deles, lançamos mão de informações de dois planos de aula que respaldam nossa discussão.

A seguir, discutimos alguns eventos que mostram o potencial reflexivo e investigativo do diário pessoal e da sessão reflexiva para analisar o processo de construção de conhecimento entre docentes. 


\section{Discussão do material empírico}

Nesta seção, discutimos como a mediação dialogada entre o professor em formação continuada (PFC) e a professora universitária (PU) (sessões reflexivas) e entre o PFC e as fontes/instrumentos (planos de aula e diário pessoal) acarretaram mudanças nas práticas do PFC.

A primeira subseção, que intitulamos de Pair work, mostra como a regulação da PU durante a sessão reflexiva contribuiu para a ocorrência de um desequilíbrio no PFC, que resultou na construção de um novo conhecimento para ele. Já a segunda, intitulada Naming students, além de mostrar a importância da colaboração, evidencia a valorização de momentos tanto informais quanto formais na formação de professores/as.

\subsection{Pair work}

Para este primeiro ponto da análise, utilizamos material empírico proveniente de duas fontes: uma sessão reflexiva e dois planos de aula. A sessão reflexiva abaixo aconteceu após a segunda aula ministrada pelo PFC, sendo ela, portanto, a primeira sessão reflexiva a acontecer entre ele e a PU. Vamos ao trecho:

[1]

PFC: So, what did you think of the class?

PU: I thought it was fun. You were very relaxed, but I thought it was too much work on pair work. For every activity you asked, there was pair work afterwards. Why did you choose to do it that way?

PFC: I don't know. I think it's because I wanted them to interact and think before saying anything.

PU: What is the purpose of this for your research? Are you going to transcribe all the talk?

PFC: I'm going to transcribe the group interactions, not the interactions they have in pairs. So, I'm gonna have to jump these. It can take a lot of time, right? Maybe I wanted it to take a lot of time because I was insecure about the class. I thought it wasn't going to last so long and then I asked them to do everything in pairs because it can last more time. I think that's why I asked them to do everything in pairs.

PU: That's a way of consuming the time of the lesson, but it's not a problem, okay? They do it in pairs, and then you open the discussion for the 
whole group. They are doing the same thing twice. But you need the data for the research, so you have to open the discussion. That's not a problem. I was just thinking: too much pair work. It's just food for thought. You think about it, when you are preparing the lessons. But, in general, it was a very good lesson. You were very comfortable in the teacher's role. (Sessão Reflexiva 1, após a Aula 2).

Neste primeiro trecho, vemos que os papéis são definidos a partir do momento em que o PFC pergunta diretamente à PU sua opinião sobre a aula. Nesse caso, o PFC, talvez por ser sua primeira sessão reflexiva, vê a PU como a fonte de conhecimento que poderá o ajudar a melhorar suas aulas. Acreditamos que seja por esse motivo que a PU afirma diretamente sua opinião sobre a aula e onde o primeiro problema se encontra. $\mathrm{Na}$ ótica da perspectiva sociocultural, a PU faz o papel, então, do par mais competente nessa mediação dialógica, que guia o PFC na tentativa de ajudá-lo a resolver o problema.

Como Ibiapina (2016) argumenta, na perspectiva da formação docente de viés colaborativo, o/a outro/a torna-se um/a parceiro/a que busca refletir sobre e ressignificar as ações implementadas, de maneira que possa levar o/a outro/a professor/a a perceber determinados aspectos que não conseguiria sozinho/a, caso não ocorresse um diálogo reflexivocolaborativo. A autora complementa que tais reflexões têm grande potencial de acarretar mudanças nas práticas de sala de aula.

A primeira questão discutida é a utilização demasiada de atividades em pares com os/as alunos/as da turma. Visto que a pergunta do PFC foi direta, a PU afirma de modo explícito o que achou da aula, mas retorna a pergunta (Why did you choose to do it that way?) a ele para que ele refletisse sobre suas ações. Ela faz o uso da mediação estratégica, definida por Johnson e Golombek (2011, p. 6-7), baseado em Wertsch (1985), como uma "assistência cognitiva que move do implícito para o explícito, é responsiva à necessidade imediata, e está mais preocupada com a transformação cognitiva do que com a performance comportamental". A PU não se mostra somente preocupada com o uso das atividades em pares, mas também, e principalmente, com o processo de reflexão que o PFC poderia fazer durante a mediação.

Para Johnson e Golombek (2011, p. 7), durante o momento da mediação estratégica, 
[a] assistência deve ser graduada - muita [assistência] (por exemplo: faça isso, faça aquilo) diminui a agência do/a aprendiz, ao passo que pouca [assistência] aumenta a frustração (ex. eu não consigo fazer isso), e ela deve ir de encontro à necessidade do/a aprendiz num determinado momento.

Numa tentativa de fazer com que o PFC reflita sobre o uso de atividades em pares durante a aula, a PU medeia estrategicamente a interação de forma graduada, como Johnson e Golombek (2011) sugerem na citação anterior. Primeiro, ela pergunta: $W$ by did you choose to do it that way?; depois, realiza outra pergunta, de modo mais específico, para que o PFC possa refletir sobre sua pesquisa de mestrado: What is the purpose of this for your research? Are you going to transcribe all the talk?; por fim, vendo que o PFC não consegue receber os reforços de forma graduada, a PU diz de modo explícito o que, em sua percepção, ele deveria ter feito: That's a way of consuming the time of the lesson, [...] [b] ut you need the data for the research, so you have to open the discussion. Podemos concluir, portanto, que a PU tenta mediar gradualmente a conversa, pois ela está preocupada com a transformação cognitiva e a agência do PFC, fazendo com que ele reflita sobre o que o uso demasiado de atividades em pares poderia implicar e o resultado disso na dinâmica de sala de aula e em sua pesquisa de mestrado. Como eles concluem, tal uso refletia uma insegurança do PFC ao ocupar a posição de professor formador pela primeira vez, o que influenciaria a geração do material empírico para sua pesquisa, pois as interações em pares, mesmo que ocupassem muito tempo da aula, não seriam transcritas.

Nas palavras de Ibiapina (2016, p. 44), “[a] colaboração, portanto, que ocorre em contexto de pesquisa acadêmica, é produzida por intermédio de interações questionadoras sobre as práticas educativas que os[/as] docentes desenvolvem". Ainda, segundo a autora, a reflexão sobre a prática deve envolver o desenvolvimento profissional e a produção de conhecimentos, ou seja, atender às necessidades da formação e da pesquisa (IBIAPINA, 2008a, 2008b). A forma como a PU age contempla os elementos mencionados, visto que ela demonstra preocupação com os objetivos estabelecidos pelo PFC, ao fazer questionamentos que pudessem contribuir com o processo.

No nosso entendimento, a interação entre a PU e o PFC é um exemplo da construção de um espaço, nesta investigação, que possibilita uma "produção significativa de saberes locais, que decorrem do esforço 
mútuo de professores[/as] em ação-pesquisa” (MATEUS, 2013a, p. 103). Nessa perspectiva, os/as docentes agem em seus contextos a partir de possibilidades que são por eles/as mesmos/as criadas (MATEUS; EL KADRI; GAFFURI, 2014).

A mudança nas ações do PFC pode ser percebida ao comparar os planos de aula de antes e depois da primeira sessão reflexiva. Ao analisar os padrões interacionais da Aula 2, podemos observar que, no planejamento, houve quatro momentos de interação em pares, como mostra o Quadro 1.

QUADRO 1 - Tipos de interação no plano da Aula 2

\begin{tabular}{|c|c|}
\hline Tipo de interação & Quantidade \\
\hline Professor-Aluno/a & 7 \\
\hline Aluno/a-Aluno/a & 4 \\
\hline Aluno/a-Grupo & 1 \\
\hline Total & 12 \\
\hline
\end{tabular}

Fonte: Elaborado pelo autor e pela autora.

A primeira sessão reflexiva aconteceu logo após a Aula 2. No Quadro 1 , vemos que para cada interação entre os/as alunos/as em pares, havia 1,75 interação entre professor e aluno/a. No Quadro 2, com o objetivo de comparação, apresentamos as informações interacionais da Aula 3.

QUADRO 2 - Tipos de interação no plano da Aula 3

\begin{tabular}{|c|c|}
\hline Tipo de interação & Quantidade \\
\hline Professor-Aluno/a & 10 \\
\hline Aluno/a-Aluno/a & 3 \\
\hline Aluno/a-Grupo/a & 1 \\
\hline Total & 14 \\
\hline
\end{tabular}

Fonte: Elaborado pelo autor e pela autora.

$\mathrm{Na}$ Aula 3, a quantidade de interação entre os pares de alunos/as cai uma unidade, ao passo que a interação professor-aluno/a aumenta três. Para cada interação entre os pares de estudantes, por conseguinte, houve 3,3 
interações entre o professor e os/as alunos/as. Apesar de não ter afirmado explicitamente que iria seguir o conselho da PU durante a sessão reflexiva, é possível que tenha ocorrido uma internalização pelo PFC da fala da PU, ao observar a diferença entre as interações planejadas na Aula 2 (antes da primeira sessão reflexiva) e na Aula 3 (após a primeira sessão reflexiva). Esse processo de internalização foi possível por causa da externalização da preocupação da professora regente durante a sessão reflexiva. A mudança aumentou o número de interações professor-aluno/a, que seriam transcritas, e o número de interações aluno/a-aluno/a, que não seriam transcritas para a pesquisa, diminuiu. Assim, podemos afirmar que houve uma mudança nas ações do PFC ao planejar as aulas do seu curso de formação.

Parece contraditório ressaltar que o trabalho em pares não é benéfico em um texto que se insere na abordagem sociocultural, mas como Donato (2000) e Mateus (2013a) pontuam, é importante considerar o aspecto circunstancial das interações. Devemos observar que, nesse contexto, a PU sugere diminuir a quantidade de atividades em pares para que mais momentos de discussão aberta em grupo ocorressem, pois o PFC não iria transcrever as interações em pares, que estavam tomando muito tempo das aulas. Além disso, a utilização demasiada de trabalhos em pares se devia ao fato de uma insegurança do PFC, que agia como professor formador da turma. Assim, concluímos que esse processo interacional entre o PFC e a PU construiu conhecimento relevante para esse determinado contexto.

\subsection{Naming students}

Nesta subseção, analisamos trechos de duas entradas no diário pessoal escrito pelo PFC e da segunda sessão reflexiva com a PU. A seguir, uma questão que preocupava o PFC era como distribuir igualmente os espaços de fala na sala de aula entre os/as estudantes. Vamos ao primeiro excerto:

[2]

I don't know if I had a classroom management problem, but they didn't talk much. And I was really pissed off because only one student talked too much and took the turn all the time. The others were silent. I talked to the professor at the end of the lesson and she suggested I should name other students when one talks too much. (Diário pessoal, após a Aula 3). 
Podemos observar no trecho acima que há um desequilíbrio cognitivo no PFC sobre a tomada de turnos de uma aluna em específico. É por meio do diário pessoal que temos acesso às reflexões concernentes a como o PFC lida com o problema. Primeiro, ele fala com a PU sobre a dúvida. Depois, ela sugere a estratégia de nomear alunos/as diferentes quando um/a estiver falando muito. Poderíamos argumentar que esse não seria um momento de formação do professor por ele não estar inserido em um contexto formal. No entanto, Johnson (2009) alega que precisamos mudar como pensamos sobre o desenvolvimento profissional. Precisamos ver que "a aprendizagem do/a professor/a é social, situada em contextos físicos e sociais, e distribuída entre pessoas, ferramentas e atividades" (JOHNSON, 2009, p. 5). Olhar para o processo de formação como distribuído entre outros elementos e locais fora de contextos formais implica em conceber "situações de aprendizagem do/a professor/a para além de atividades de desenvolvimento profissional visíveis, como cursos, workshops, seminários, para incluir as relações informais tanto profissionais quanto sociais do/a docente" (JOHNSON, 2009, p. 6).

O diário escrito pelo PFC conseguiu funcionar como uma ferramenta para capturar esse pequeno momento de formação e reflexão informal, em que ele estava com um problema e utilizou a fonte diário para exteriorizar seu desequilíbrio cognitivo, ou seja, a aprendizagem acontece de forma distribuída não somente por meio de pessoas, mas de ferramentas, podendo acontecer em situações informais. Nessa linha de raciocínio, como Mateus (2013a, p. 106) argumenta, as ferramentas que usamos não são meramente um meio para nossos fins, mas objetos que participam da recriação de nossos planos e perspectivas, "nos permitindo aprender e transformar nossas experiências".

O trecho seguinte é parte da segunda sessão reflexiva, em que o PFC e a PU refletem sobre a estratégia utilizada:

[3]

PU: What did you think about the lesson?

PFC: What did $I$ think about the lesson? I think it was nice. I was very calm, and I didn't want to hurry things up. I did only half of the lesson plan.

PU: Really? I thought it was such a long lesson. I mean, you did many things.

PFC: But they were really engaged. 
PU: Yes, everybody was participating.

PFC: But I liked the class.

PU: Did you notice the difference with the absence of [...] [the student who talks a lot]?

PFC: Yes. [Another student] [...] even told me at the end of the lesson that it was much better without her. [...] But I liked the class today. I think there was more space for them to express their opinions and to talk more.

PU: I think they are getting used to you as a professor and the type of lesson that you are preparing, and they want to participate. They are all engaged. So, it's very cohesive in my opinion. [...]. And today I saw that you were naming the students.

PFC: Yes, I used the strategy you suggested.

$\mathrm{PU}$ : And you bave to continue using it. And you can interfere if the girls are holding the floor. (Sessão Reflexiva 2, após a Aula 4).

Há uma diferença entre o início da primeira sessão reflexiva e da segunda sessão reflexiva. A primeira pergunta da sessão anterior era $S o$, what did you think of the class?, sendo feita pelo PFC e dirigida à PU. Já na sessão seguinte, a PU pergunta primeiro para o PFC o que ele achou da aula. Vemos que, na perspectiva colaborativa e sociocultural, os papéis não são definidos previamente, mas definidos no momento de interação (FIGUEIREDO, 2018; SOUSA, 2016; SOUSA et al., 2019). Corroboramos a ideia de que "colaboração não se caracteriza unicamente como conceito pré-determinado, com scripts pré-estabelecidos para ação, mas como processo empreendido por pessoas capazes de gerar co-laboração a partir da adesão aberta à práxis colaborativa" (MATEUS; EL KADRI; GAFFURI, 2014, p. 71, grifo no original). Ademais, salientamos que, nessa sessão reflexiva, a PU tenta fazer com que o PFC seja o responsável por sua reflexão, contrário ao que acontece na anterior.

A maioria dos comentários durante essa sessão estão relacionados à participação dos/as alunos/as, tema sobre o qual o PFC almejava ter mais domínio. A partir dos comentários sobre a participação (everybody was participating; I think there was more space for them to express their opinions and to talk more), vemos que a avaliação da aula por ele foi feita de forma positiva. Com base na sessão, a aula foi mais positiva, pois: 1) a falta da aluna que dominava as interações colaborou para uma dinâmica de turnos mais eficiente durante a aula ([Another student $][. .$.$] even told me at the end of the lesson that it was much$ 
better without her); e 2) o PFC utilizou a estratégia sugerida pela PU (And today I saw that you were naming the students).

Por último, os argumentos apresentados no diário, após a Aula 4, e na segunda sessão reflexiva também mostram a aprovação da estratégia de nomear os/as alunos/as. O PFC afirma que essa estratégia permitiu uma participação mais igualitária. Além disso, há um feedback positivo de uma aluna, a mesma que é mencionada na sessão reflexiva, dizendo que havia gostado da aula. Aqui, o PFC afirma novamente que ela gostou da aula, pois a condução e a estratégia de nomear estudantes para falar permitiu que o espaço de fala fosse mais compartilhado. Vejamos:

[4]

I enjoyed the lesson because students participated more equally. I had planned lots of things and we didn't get to finish half of the lesson plan. One student who controls the turns didn't go to class, and I believe that this is one of the reasons why the class was better. But there is something more: I followed the strategy of naming students so otherpeople could speak. And it worked. One student even said at the end of the lesson that she liked the way I conducted the class by naming students and allowing others to speak. (Diário pessoal, após a Aula 4).

Consideramos que os diálogos feitos pelo PFC com a PU foram colaborativos por permitirem a coconstrução de conhecimentos e a resolução de problemas (IBIAPINA, 2008a, 2008b; SWAIN, 2000). Como Ibiapina (2008b, p. 32) assevera, "cada partícipe presta sua contribuição específica", isto é, contribui para beneficiar o projeto de determinada maneira. Para a autora, a colaboração entre professores/as é caracterizada por "relações mais igualitárias e democráticas voltadas para o desenvolvimento de novos conhecimentos, novas compreensões e possibilidades de ação" (IBIAPINA, 2008a, p. 18), aspectos que podem ser percebidos nos diálogos entre a PU e o PFC.

Além disso, esse processo de formação envolveu aspectos formais (escrita do diário pessoal, realização das sessões reflexivas, que foram gravadas) e informais (conversas com a PU e com a aluna sobre a aula e a participação, ambas sem a gravação), ressaltando a importância de uma formação de professores/as a partir de uma perspectiva da abordagem sociocultural (JOHNSON, 2006, 2009), que considera ambos os momentos como relevantes para o desenvolvimento docente profissional. 
Por fim, para construir o conhecimento descrito acima, alguns passos foram seguidos, como: externalização do problema; formulação de possibilidades para a tentativa de solução/mitigação do problema; teste de tais possibilidades; reflexão sobre sua implementação e sobre os resultados; e reflexão e feedback sobre os eventos ocorridos a partir de uma terceira pessoa. Esse movimento de mediação entre professor-professora, professor-aluna, professor-diário, professor-sessão reflexiva foi crucial para o desenvolvimento do conhecimento gerado concernente à estratégia de nomear alunos/as.

\section{Considerações finais}

A mudança de paradigma, do positivista para o interpretativista, em pesquisas na formação de professores/as permitiu uma nova agenda de estudos: a de utilizar pressupostos da abordagem sociocultural para analisar os processos de formação docente (JOHNSON, 2006, 2009; MATEUS, 2013a, 2013b; VIEIRA-ABRAHÃO, 2012). O interesse da perspectiva sociocultural na formação de professores/as está em promover um questionamento das práticas para a construção de conhecimentos situados, contextuais e relevantes para os contextos em que os/as docentes atuam. Essa perspectiva difere da positivista por acreditar que não se deve insistir na ideia da generalização sobre o que um/a bom/boa professor/a deve ou não fazer.

Neste artigo, nosso objetivo foi analisar o processo de construção de conhecimento entre um professor em formação continuada e uma professora universitária a partir da mediação dialogada em sessões reflexivas e da escrita de um diário pessoal, com o suporte complementar de informações provenientes de dois planos de aula. Na discussão, analisamos dois momentos de construção de conhecimentos, que fizeram parte da formação do professor mestrando: a) o planejamento das aulas, em um primeiro momento, com o foco nas interações entre os/as alunos/as; e b) a nomeação dos/as alunos/as em sala de aula como estratégia para mediar o espaço de fala dos/as estudantes.

No primeiro evento, intitulado Pair work, a mediação estratégica da professora universitária nas sessões reflexivas com o professor em formação continuada provocou mudanças nas práticas educacionais dele. Além disso, 
as sessões evidenciaram que o uso demasiado de atividades em pares refletia uma insegurança do professor, ao ministrar aulas como docente formador pela primeira vez. Assim, mostramos que houve mudança nos padrões interacionais na aula dele após a sessão reflexiva. O professor optou por diminuir as interações em pares e aumentar as interações entre professor e alunos/as para atingir seu objetivo.

Já no segundo evento, Naming students, o diálogo colaborativo entre a professora universitária e o professor em formação continuada e o feedback da aluna do curso permitiram, respectivamente, a resolução de problemas e, depois, a confirmação de mudanças bem-sucedidas no decorrer do curso. $\mathrm{O}$ professor foi capaz de ter mais controle sobre a dinâmica da aula ao nomear alunos/as para participar das interações. Além disso, essa seção também evidenciou que a formação docente pode acontecer tanto em momentos formais quanto informais.

Vimos também que a mediação estratégica e o diálogo colaborativo foram fundamentais para a construção de conhecimento e para o desenvolvimento da agência do professor em formação. Por fim, esta pesquisa ressalta a importância da colaboração na construção de conhecimentos úteis para a prática de professores/as de línguas.

\section{Agradecimentos}

Agradecemos à Coordenação de Aperfeiçoamento de Pessoal de Nível Superior (CAPES) por seu auxílio financeiro.

\section{Contribuição dos Autores}

Como pós-graduandos/as do Programa de Pós-graduação em Letras e Linguística da Universidade Federal de Goiás, cursamos a disciplina Ensino e aprendizagem de línguas estrangeiras, ministrada pelo professor Francisco José Quaresma de Figueiredo e pela professora Neuda Alves do Lago. A partir dessa experiência, tivemos acesso, lemos e discutimos os mesmos textos. $\mathrm{O}$ artigo foi escrito colaborativamente. A geração do material empírico foi realizada pelo primeiro autor. A discussão, a escrita e a revisão do texto foram realizadas de forma conjunta entre o autor e a autora. 


\section{Referências}

AHMED, M. K. Speaking as Cognitive Regulation: A Vygotskian Perspective on Dialogic Communication. In: LANTOLF, J.; APPEL, G. (ed.). Vygotskian Approaches to Second Language Research. New Jersey: Ablex Publishing Corporation, 1994. p. 157-171.

BANKS-LEITE, L. As dimensões interacionistas e construtivistas em Vygotsky e Piaget. Caderno Cedes, Campinas, ano XX, n. 24, p. 31-37, 2000.

DONATO, R. Sociocultural Contributions to Understanding the foreign and second language classroom. In: LANTOLF. J. P. (ed.). Sociocultural Theory and Second Language Learning. Oxford: Oxford University Press, 2000. p. 27-50.

FIGUEIREDO, F. J. Q. A aprendizagem colaborativa de línguas: considerações conceituais e aplicações em distintos contextos. In: FIGUEIREDO, F. J. Q. (org.). A aprendizagem colaborativa de línguas. 2. ed. Goiânia: Editora da UFG, 2018. p. 13-58.

IBIAPINA, I. M. L. M. A conquista: pesquisadores e professores pesquisando colaborativamente. In: LOUREIRO JR., E.; IBIAPINA, I. M. L. M. (org.). Videoformação, reflexividade crítica e colaboração: pesquisa e formação de professores. Belo Horizonte: Autêntica, 2008a. p. 11-28.

IBIAPINA, I. M. L. M. Pesquisa colaborativa: investigação, formação e produção de conhecimentos. Brasília: Líber Livros, 2008b. 134p.

IBIAPINA, I. M. L. M. Reflexões sobre a produção do campo teóricometodológico das pesquisas colaborativas: gênese e expansão. In: IBIAPINA, I. M. L. M.; BANDEIRA, H. M. M.; ARAÚJO, F. A. M. (org.). Pesquisa colaborativa: multirreferenciais e práticas convergentes. Teresina: EDUFPI, 2016. p. 33-62.

JOHNSON, K. E. The Sociocultural Turn and Its Challenges for Second Language Teacher Education. TESOL Quarterly, [S.l.], v. 40, n. 1, p. 235-257, 2006. DOI: https://doi.org/10.2307/40264518

JOHNSON, K. E. Second Language Teacher Education: A Sociocultural Perspective. New York: Routledge, 2009. 148p. DOI: https://doi.org/10.4324/9780203878033

JOHNSON, K. E.; GOLOMBEK, P. R. A Sociocultural Theoretical Perspective on Teacher Professional Development. In: . (ed.). Research on Second Language Teacher Education: A Sociocultural Perspective on Professional Development. New York: Routledge, 2011. p. 1-12. DOI: https://doi.org/10.4324/9780203844991 
LANTOLF, J. P.; APPEL, G. Theoretical Framework: An Introduction to Vygotskian Approaches to Second Language Research. In: (ed.). Vygotskian Approaches to Second Language Research. New Jersey: Ablex Publishing Corporation, 1994. p. 1-32.

MATEUS, E. Conversa com Elaine Mateus. In: SILVA, K. A.; ARAGÃO, R. C. (org.). Conversas com formadores de professores de linguas. Campinas: Pontes, 2013a. p. 122-128.

MATEUS, E. Práticas de formação colaborativa de professores/as de inglês: representações de uma experiência no Pibid. Revista Brasileira de Linguística Aplicada, Belo Horizonte, v. 13, n. 4, p. 1107-1130, 2013b. DOI: https://doi.org/10.1590/ S1984-63982013005000027

MATEUS, E.; EL KADRI, M. S.; GAFFURI, P. Dinâmicas de colaboração como prática social de aprendizagem significativa. Calidoscópio, São Leopoldo, RS, v. 12, n. 1, p. 64-72, 2014. DOI: https://doi.org/10.4013/cld.2014.121.07

MERRIAM, S. Case Studies as Qualitative Research. In: Qualitative Research and Case Study Applications in Education. San Francisco, CA: Jossey-Bass, 1998. p. 26-43.

MERRIAM, S. Introduction to Qualitative Research. In: -Qualitative Research in Practice: Examples for Discussion and Analysis. San Francisco: Jossey-Bass, 2002. p. 3-17.

SILVESTRE, V. P. V. Construção colaborativa de um plano de aula de inglês em um contexto do PIBID: um olhar a partir da perspectiva sociocultural. Atos de Pesquisa em Educação (FURB), Blumenau, SC, v. 9, n. 3, p. 641-661, 2014. DOI: https://doi. org/10.7867/1809-0354.2014v9n3p641-661

SOUSA, L. P. Q. Analisando os aspectos emergentes e as percepções dos alunos sobre uma produção de escrita em pares: uma experiência em uma sala de aula de língua inglesa. Travessias, Cascavel, PR, v. 10, n. 1, p. 331-352, 2016.

SOUSA, L. P. Q.; TIRABOSCHI, F. F.; LAGO, N. A.; FIGUEIREDO, F. J. Q. Collaborative English Language Learning: Some Reflections from Interactions Between Pairs. Trabalhos em Linguística Aplicada, Campinas, v. 58, n. 1, p. 259-286, 2019. DOI: https://doi.org/10.1590/010318138653439430941

SWAIN, M. The Output Hypothesis and Beyond: Mediating Acquisition Through Collaborative Dialogue. In: LANTOLF, J. P. (ed.). Sociocultural Theory and Second Language Learning. Oxford: Oxford University Press, 2000. p. 97-114. 
TUDGE, J. Vygotsky, the Zone of Proximal Development, and Peer Collaboration: Implications for Classroom Practice. In: MOLL, L. C. (ed.). Vygotsky and Education: Instructional Implications and Applications of Sociohistorical Psychology. Cambridge: Cambridge University Press, 1990. p. 155-172. DOI: https://doi. org/10.1017/CBO9781139173674.008

VIEIRA-ABRAHÃO, M. A formação do professor de línguas de uma perspectiva sociocultural. Signum. Estudos de Linguagem, Londrina, PR, v. 15, n. 2, p. 457-480, 2012. DOI: https://doi.org/10.5433/2237-4876.2012v15n2p457

VYGOTSKY, L. A teoria de Piaget sobre a linguagem e o pensamento das crianças. In: . Pensamento e linguagem. São Paulo: Summus, 1993. p. 11-21.

VYGOTSKY, L. S. A formação social da mente: o desenvolvimento dos processos psicológicos superiores. Trad. José Cipolla Neto, Luis Silveira Menna Barreto, Solange Castro Afeche. 6. ed. São Paulo: Martins Fontes, 1998.

Data de submissão: 27/02/2020. Data de aprovação: 14/09/2020. 